NASA Technical Memorandum 107095

AIAA-95-2631

\title{
Human Lunar Mission Capabilities Using SSTO, ISRU and LOX-Augmented NTR Technologies- A Preliminary Assessment
}

Stanley K. Borowski

Lewis Research Center

Cleveland, Ohio

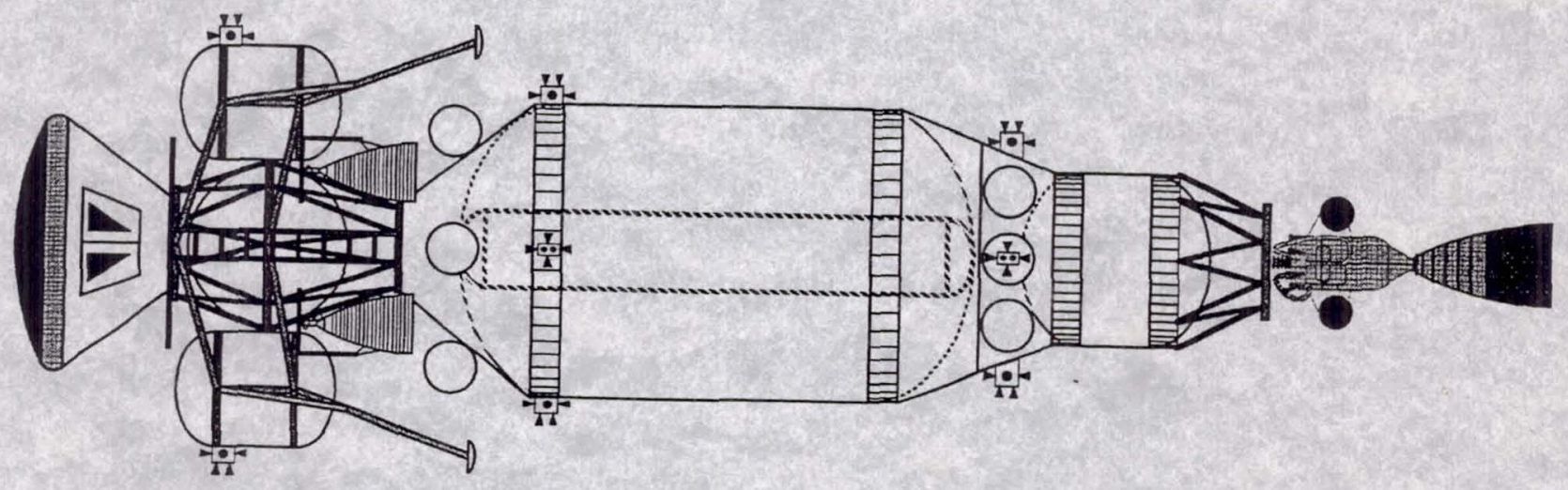

Prepared for the

31st Joint Propulsion Conference and Exhibit cosponsored by AIAA, ASME, SAE, and ASEE

San Diego, California, July 10-12, 1995

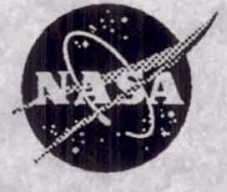

National Aeronautics and Space Administration

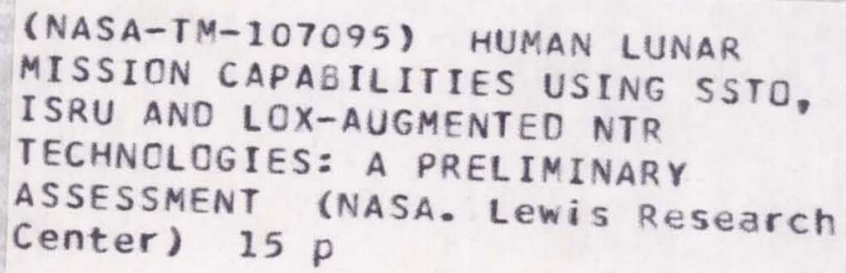




\title{
HUMAN LUNAR MISSION CAPABILITIES USING SSTO, ISRU AND LOX-AUGMENTED NTR TECHNOLOGIES --A PRELIMINARY ASSESSMENT
}

\author{
Stanley K. Borowski * \\ NASA Lewis Research Center \\ Cleveland, $\mathrm{OH} 44135$
}

\section{ABSTRACT}

The feasibility of conducting human missions to the Moon is examined assuming the use of three "high leverage" technologies: (1) a single-stage-toorbit (SSTO) launch vehicle, (2) "in-situ" resource utilization (ISRU)--specifically "lunar-derived" liquid oxygen (LUNOX), and (3) LOX-augmented nuclear thermal rocket (LANTR) propulsion. Lunar transportation system elements consisting of a LANTR-powered lunar transfer vehicle (LTV) and a chemical propulsion lunar landing / Earth return vehicle (LERV) are configured to fit within the "compact" dimensions of the SSTO cargo bay (diameter: $4.6 \mathrm{~m} / \mathrm{length}: 9.0 \mathrm{~m}$ ) while satisfying an initial mass in low Earth orbit (IMLEO) limit of $\sim 60 \mathrm{t}$ (3 SSTO launches). Using $\sim 8 \mathrm{t}$ of LUNOX to "reoxidize" the LERV for a "direct return" flight to Earth reduces its size and mass allowing delivery to LEO on a single $20 \mathrm{t}$ SSTO launch. Similarly, the LANTR engine's ability to operate at any oxygen/hydrogen mixture ratio from 0 to 7 with high specific impulse ( 940 to $515 \mathrm{~s}$ ) is exploited to reduce hydrogen tank volume, thereby improving packaging of the LANTR LTV's "propulsion" and "propellant modules". Expendable and reusable, piloted and cargo missions and vehicle designs are presented along with estimates of LUNOX production required to support the different mission modes. Concluding remarks address the issue of lunar transportation system costs from the launch vehicle perspective.

\section{INTRODUCTION}

Future human exploration missions to the Moon will require an "economical" lunar transportation system (LTS) providing efficient "access to and through space." Utilizing locally available resources--specifically "iron oxide (FeO)- rich" mare soils and impact / volcanic glass-- to produce LUNOX will also be key to minimizing IMLEO, the size and number of LTS elements, and the cost for each lunar mission. At present, NASA is focusing considerable resources on the construction of the international space station (ISS) and on development and demonstration of a reusable, single-stage-to-orbit (SSTO) vehicle 1 to replace the current Space Shuttle in the post-2005 timeframe. It is envisioned that an industry-developed andoperated SSTO would have an average flight rate of $\sim 40$ missions per year with $\sim 50 \%$ of these flights procured by NASA to provide logistics resupply to the ISS.

Planning future human missions to the Moon and Mars is also beginning anew--albeit in a less dramatic fashion than the previous Space Exploration Initiative2--in response to the "Human Exploration and Development of Space" (HEDS) component of NASA's just released strategic plan. 3 Activities are focusing on the development of key "high leverage" technologies and systems, their demonstration on precursor missions, and on the identification of viable mission architectures that could be supported by NASA in the future given the expected tight budgets and the trends toward commercialization.

This paper addresses the feasibility of conducting human lunar missions using SSTO, ISRU and LOX-augmented nuclear thermal rocket (LANTR) technologies/systems. For "access to space," the lure of the SSTO is its full reusability, improved operability, high flight rate and reduced launch costs estimated at $\sim 40 \mathrm{M} \$$ per flight. 4 Its lift capability is limited, however, and varies from $\sim 25$ $\mathrm{klbm}(\sim 11.3 \mathrm{t})$ to $45 \mathrm{klbm}(\sim 20.4 \mathrm{t})$ depending on the

${ }^{*}$ Ph.D./Nuclear Engineering, Senior Member AIAA 
low Earth orbit (LEO) altitude and its inclination. The SSTO's cargo bay volume is also small ( 50 to $75 \%$ that of the current Space Shuttle) which makes packaging of payload and LTS elements a particular challenge.

The development of LUNOX production, storage and tanker transport / transfer technologies and systems for "reoxidizing" expendable lunar landing/Earth return vehicles (LERVs) initially, and then reusable, lunar landing and transfer vehicles (LLVs and LTVs) is expected to dramatically reduce IMLEO requirements, the number of SSTO launches and the cost of delivering payload to the lunar surface. For example, with $\sim 7$ kilograms of mass required in LEO for each kilogram of mass landed on the lunar surface, the ability to reoxidize an LERV with $~ 8$ tons of LUNOX for a "direct Earth return" mission would save three 20 t-class SSTO launches compared to an "all Earth-supplied" mission requiring twice that number.

To improve "access through space," a LANTRbased LTV mission scenario has been assumed. The ability to alter the engine's thrust and specific impulse (Isp) by varying the liquid oxygen-to-liquid hydrogen ( $\mathrm{LOX} / \mathrm{LH}_{2}$ ) mixture ratio (MR) in LANTR's "LOX-afterburner" nozzle leads to small engines (both in terms of physical size and reactor power output) capable of providing "big engine" performance. Supersonic combustion of LOX with reactor preheated hydrogen emerging from the engine's sonic throat also results in higher Isp values than $\mathrm{LOX} / \mathrm{LH}_{2}$ chemical engines operating at the same mixture ratio $(\sim 100 \mathrm{~s}$ at $M R=6)$. Lastly, the increased use of high-density LOX in place of lowdensity $\mathrm{LH}_{2}$ reduces hydrogen tank volume and improves LTV component packaging within the "volume-constrained" SSTO cargo bay.

This paper describes results of preliminary system and mission analysis conducted by Lewis Research Center for NASA Headquarters' Advanced Concepts Office over the past two months. The paper first discusses the relevant technologies and describes their characteristics. Mission and transportation system ground rules and assumptions are then presented along with a description of the reference lunar mission scenario. Next, a comparison of different LTS element options--both for the LERV and LTV--is provided and the requirements/performance gains from transitioning from an expendable to reusable LTS architecture are discussed. The paper concludes with a discussion of lunar transportation system and launch vehicle costs.
SSTO, LUNOX, AND LANTR TECHNOLOGY DESCRIPTION

The SSTO Reusable Launch Vehicle

In January 1993, NASA initiated a comprehensive "in-house" study called "Access to Space." The goals of the study were to identify attractive options for the next generation of U.S. launch vehicles which would: (1) allow major reductions in the cost of space transportation (by at least $50 \%$ ); (2) provide an order of magnitude increase in crew flight safety; and (3) substantially improve overall system operability. The study examined three major architectural options which included: retaining and upgrading the current Space Shuttle and expendable launch vehicle fleet (Option 1); developing new expendable vehicles using conventional technologies (Option 2); and developing new reusable vehicles using advanced technology (Option 3). A conservative "launch needs" mission model was defined and used in the study. 4 It included all U.S. civilian (NASA), defense and commercial missions anticipated during the period 1995 through 2030, but did not consider future human missions to the Moon and Mars--a major omission.

In its final summary report 4 issued in January 1994, NASA concluded that a fully reusable, purerocket SSTO (SSTO-R) launch vehicle was the most attractive/beneficial option for development. The preferred Option 3 reference vehicle described in the "Access to Space Study" Summary Report 4 is shown in Figure 1. It is a vertical takeoff, horizontal-landing winged concept with a circular cross-section fuselage for structural efficiency (other configurations are presently being examined under NASAsupported industry contracts). It uses aluminumlithium (Al/Li) cryotanks, graphite composite material for all non-pressurized primary structure and a tripropellant (LOX/LH $\mathrm{H}_{2} / \mathrm{RP}$ ) propulsion system employing seven RD-704 engines. The payload bay is located horizontally between the forward LOX tank and the $\mathrm{LH}_{2}$ tank positioned in the vehicle's midsection. The crew cabin is situated on top of the vehicle next to an airlock/work-station area which provides crew access to both the payload bay and the ISS through an overhead hatch. A "LOX/LH ${ }_{2}$ " version of the SSTO-R would have an overall length and diameter $\sim 15 \%$ larger than its tripropellant counterpart and a gross liftoff weight (GLOW) of $\sim 2.48$ million pounds ( 1125 $t)$.

The reference SSTO-R cargo bay is 15 feet $(\sim 4.6 \mathrm{~m})$ in diameter and 30 feet $(\sim 9.15 \mathrm{~m})$ long. A 


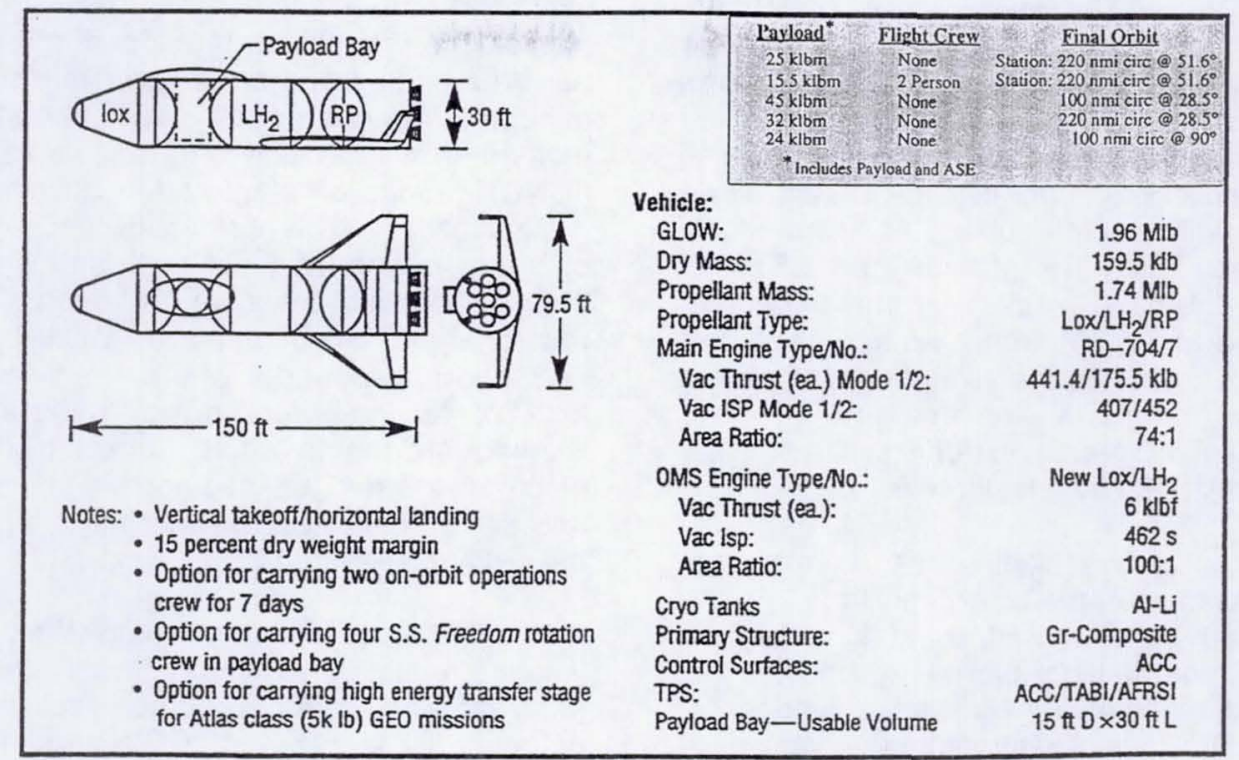

Fig. 1 Characteristics of Reference SSTO Launch Vehicle (Ref. 4)

"stretched" tripropellant vehicle configuration with a 45 foot $(13.7 \mathrm{~m})$ long payload bay and capable of delivering $\sim 20$ t to LEO (185 km/28.5 degrees inclination) was also developed. Because of the tripropellant vehicle's smaller $\mathrm{LH}_{2}$ tank, the 45 foot bay could also be placed longitudinally in the vehicle. The 45 foot SSTO-R design could also accommodate the larger DOD Titan IV-class payloads. As a result, this vehicle option showed the lowest annual operating costs ( 1.4 B $\$$ year), as well as cost per launch $(\sim 38 \mathrm{M} \$)$ and per pound of payload to LEO $(\sim 920 \$ / \mathrm{lbm})$ of the three options examined (see Table 1).

Table 1. Summary of Launch Vehicle Option Costs (Ref. 4)

\begin{tabular}{|c|c|c|c|c|c|c|}
\hline \multirow{2}{*}{\multicolumn{2}{|c|}{$\begin{array}{l}\therefore \text { Current Space Shuttle capabiitty (no ASRM) } \\
\therefore \text { In the out-years } \\
\text { - Constant FY94 dollars; no 'new ways of doing business." }\end{array}$}} & \multirow{2}{*}{$\begin{array}{l}\text { Current } \\
\text { Program }\end{array}$} & \multirow{2}{*}{$\begin{array}{l}\text { Option 1 } \\
\text { (Retrofit + } \\
\text { ELV Fleet) } \\
\end{array}$} & \multirow{2}{*}{$\begin{array}{l}\text { Option } 2 \\
\text { (Lg. + Sm. Veh. } \\
\text { + Delta) }\end{array}$} & \multicolumn{2}{|c|}{ Option 3} \\
\hline & & & & & $\begin{array}{c}\text { (SSTO-R, 30-ft } \\
\text { Bay + Titan) }\end{array}$ & \begin{tabular}{|l} 
(SSTO-R, \\
45-ft Bay)
\end{tabular} \\
\hline \multirow{5}{*}{ Costs } & Technology & 0 & $\begin{array}{l}\text { Incl. in } \\
\text { DDT\&E }\end{array}$ & SO.4B & S0.9B & $\$ 0.9 B$ \\
\hline & $\begin{array}{l}\text { DOT\&E } \\
\text { (Incl. Technology) }\end{array}$ & 0 & $\$ 2.4 B$ & $\$ 11.1 \mathrm{~B}$ & $\$ 17.6 \mathrm{~B}$ & S18B \\
\hline & Production & 0 & $\$ 5.6 B$ & $\$ 2.08$ & $\$ 18.1 \mathrm{~B}$ & $\$ 18.7 B$ \\
\hline & $\begin{array}{l}\text { Operations } \\
\text { (Out-Years) }\end{array}$ & $\$ 6.4 \mathrm{~B} / \mathrm{yr}$ & $\$ 6.1 \mathrm{~B} / \mathrm{yr}$ & $\$ 4.0 B / y T$ & $\$ 2.6 \mathrm{~B} / \mathrm{yr}$ & $\$ 1.4 \mathrm{~B} / \mathrm{yT}$ \\
\hline & Life-Cycle Costs & $\$ 233 B$ & $\$ 230 B$ & $\$ 192 B$ & $\$ 198 B$ & S169B \\
\hline \multirow{4}{*}{$\begin{array}{l}\text { Operations } \\
\text { Cost } \\
\text { Metries". }\end{array}$} & $\begin{array}{l}\text { Average \$naunch } \\
\text { (Shuttle Replacement) }\end{array}$ & $\begin{array}{l}\text { \$322M } \\
\text { (STS)" }\end{array}$ & $\begin{array}{l}\$ 293 \mathrm{M} \\
\text { (STS) }\end{array}$ & $\begin{array}{l}\text { \$85M (Sm.) } \\
\$ 205 \mathrm{M}(\mathrm{Lg} .)\end{array}$ & $\$ 41 M$ & $\$ 38 M$ \\
\hline & $\begin{array}{l}\text { SAb of Payload } \\
\text { (Feet Average for } \\
\text { Mission Moder) }\end{array}$ & $\$ 7,488 / \mathrm{b}$ & $\$ 6,814 / \mathrm{b}$ & $\$ 6,100 / b$ & $\$ 3,900 / \mathrm{b}$ & $\$ 2,100 / \mathrm{b}$ \\
\hline & $\begin{array}{l}\text { SAb of Payioad } \\
\text { (Full Veh., to LEO, 28 }\end{array}$ & $\begin{array}{l}\$ 6,850 / \mathrm{b} \\
(\mathrm{STS})^{*}\end{array}$ & $\begin{array}{l}\$ 6,234 / \mathrm{b} \\
(\mathrm{STS})^{*}\end{array}$ & 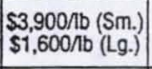 & $\$ 980 / \mathrm{b}$ & $\$ 920 / \mathrm{b}$ \\
\hline & $\begin{array}{l}\text { SAb of Payload } \\
\text { (to the Space Station) }\end{array}$ & $\$ 12,880 / \mathrm{b}$ & $\$ 11,720 / \mathrm{b}$ & $\$ 3,700 / \mathrm{b}(\mathrm{Lg})$. & $\$ 1,600 / \mathrm{b}$ & $\$ 1,500 / \mathrm{b}$ \\
\hline
\end{tabular}




\section{LUNOX Production and Utilization}

Lunar -derived oxygen (LUNOX) has been identified 5 as the most promising initial resource to be developed on the lunar surface. A local source of LOX could replenish life support systems, and fuel cells used to power electric surface vehicles. Most importantly, the ability to provide the LERV's "oxygen-rich" chemical rocket engines (which typically operate at $M R=6$ ) with a source of return propellant oxidizer reduces the size and mass of the LERV, as well as, the LTV which delivers it to low lunar orbit (LLO). This "feedback effect" can cut the required mission IMLEO by a factor of 2 .

Oxygen is also attractive as a resource because it is abundant in the lunar regolith ( $45 \%$ by mass) 5 and can be extracted using a variety of techniques. 6 Two of the more promising concepts for oxygen production involve hydrogen reduction of ilmenite $\left(\mathrm{FeTiO}_{3}\right)$ in high-titanium mare soil and ferrous iron in volcanic glass. 7 Oxygen production via hydrogen reduction is a two step process. First, the iron oxide $(\mathrm{FeO})$ in ilmenite or volcanic glass is reduced and oxygen is liberated to form water:

$$
\begin{aligned}
& \mathrm{FeTiO}_{3}(\mathrm{~s})+\mathrm{H}_{2}(\mathrm{~g}) \rightarrow \mathrm{Fe}(\mathrm{s})+\mathrm{TiO}_{2}(\mathrm{~s})+\mathrm{H}_{2} \mathrm{O}(\mathrm{g}) \\
& \text { or } \\
& \mathrm{FeO}(\mathrm{s})+\mathrm{H}_{2}(\mathrm{~g}) \longrightarrow \mathrm{Fe}(\mathrm{s})+\mathrm{H}_{2} \mathrm{O}(\mathrm{g})
\end{aligned}
$$

Next, the water vapor is electrolyzed to regenerate the hydrogen reactant and oxygen resource. The hydrogen is recycled back to react with more lunar feedstock while the oxygen is liquified and stored in "well-insulated" storage tanks.

Reduction experiments 7 on samples of hightitanium mare soil and iron-rich volcanic glass collected during the Apollo 17 mission to the TaurusLittrow region of the Moon have produced significant amounts of oxygen. Yields of $\sim 3.0$ weight percent (wt \%) have been measured for ilmenite-rich, titanium soil at a reduction temperature of $\sim 1050 \mathrm{C}$ after 3 hours. Using the iron-rich "orange" volcanic glass, a yield of $\sim 5.1 \mathrm{wt} \%$ was achieved at $\sim 1100 \mathrm{C}$ over the same time period. These experimental reults suggest that iron- and titanium-rich soils and iron-rich glasses, in particular, would be attractive feedstocks for lunar oxygen production. In addition to each existing in large quantities on the Moon, both are fined grained and friable and could be used with little or no processing prior to reduction. This is very important because reduced mining and benefication of bulk regolith can lower the mass and power requirements of a LUNOX production plant.

Because the lunar mission architecture examined here assumes that LUNOX is available to support the first piloted mission, cargo missions will be required in advance to establish the necessary mining infrastructure on the lunar surface. It is envisioned 8 that initial cargo flights will deliver the LUNOX production plant and nuclear power supply. A reactor sytem is preferred because it allows operation during the lunar night and is less massive than a photovoltaic system with energy storage. The reactor would be mounted on a small teleoperated cart and transported a safe distance away from the LUNOX facilty before power generation begins. Subsequent flights would deliver high duty-cycle, electric vehicles for loading and handling regolith and transporting LUNOX from the production site to the LERV (see Figure 2).

The mass and power requirements for a lunar ilmenite reduction facility producing $\sim 24 \mathrm{t}$ of LUNOX per year (enough for 3 piloted missions) have been estimated 8,9 at $\sim 17.3$ to $20.7 \mathrm{t}$, and $\sim 40$ to $80 \mathrm{~kW}_{\epsilon}$, respectively, with system mass and power variations depending on specific assumptions. A breakdown of system element masses for Jooston's 820.7 t estimate includes the LUNOX plant $(7.3 \mathrm{t})$, and nuclear reactor system $(5.1 \mathrm{t}), 2$ regolith loaders (3.5 t), and haulers (1.9 t), and 2 LUNOX tanker vehicles (2.9 t).

\section{The LOX-Augmented NTR (LANTR)}

The recently proposed LANTR propulsion concept 10,11 represents an innovative combination of conventional $\mathrm{LH}_{2}$-cooled NTR and supersonic combustion ramjet (scramjet) technologies. The LANTR engine (see Figure 3 ) utilizes the large divergent section of the NTR nozzle as an "afterburner" into which LOX is injected and supersonically combusted with reactor-heated hydrogen emerging from the LANTR's choked sonic throat--"scramjet propulsion in reverse". By varying the LOX- to- $\mathrm{LH}_{2}$ mixture ratio (MR), the LANTR engine can operate over a wide range of thrust and Isp values while the reactor produces a relatively constant power output. As the MR varies from 0 to 7 , the engine thrust - to - weight ratio for a $15 \mathrm{klbf}$ NTR increases by $\sim 440 \%$--from 3 to 13 --while the Isp decreases by only $\sim 45 \%$--from 940 to 515 seconds.

The ability to vary LANTR engine performance with MR also results in important engine-, vehicle-, and mission-benefits. Thrust augmentation allows "big engine" performance to be obtained using smaller, more affordable, easier to test NTR engines. Burn times are also shortened which extends engine life and improves "life cycle costs"--an important consideration in reusable mission architectures. 


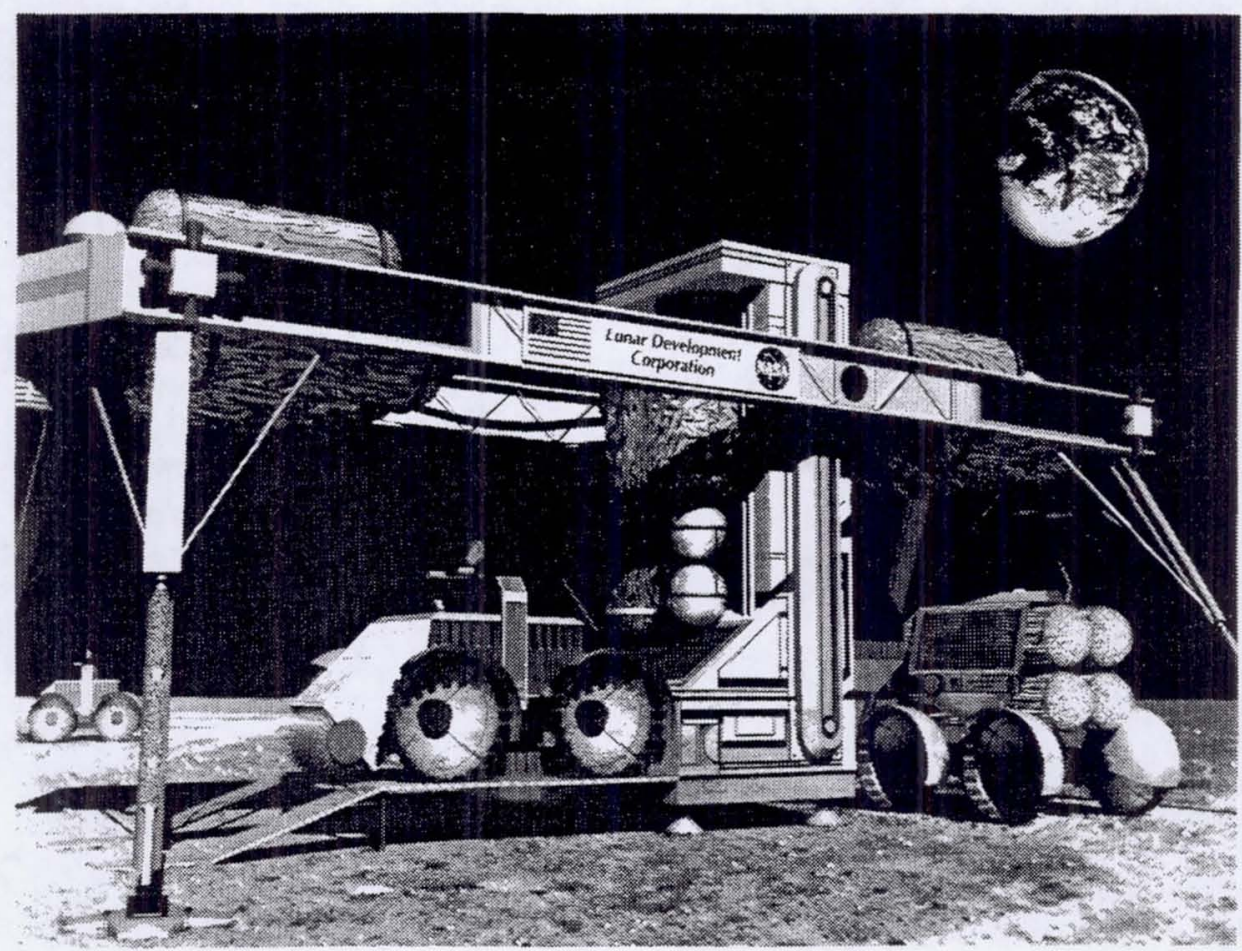

Fig. 2 "LUNOX" Facility and Teleoperated Support Vehicles

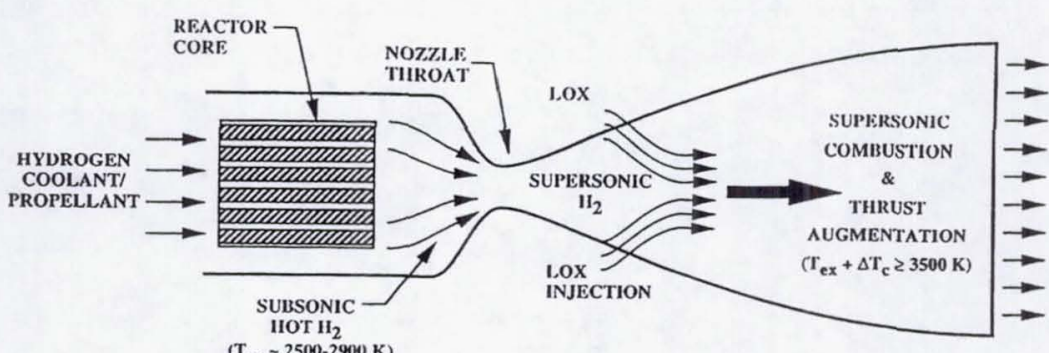

$\left(\mathrm{T}_{\mathrm{cx}} \sim 2500-2900 \mathrm{~K}\right)$

\begin{tabular}{|c|c|c|c|c|c|}
\hline \multirow[b]{2}{*}{$\begin{array}{l}\text { Life (hrs.) } \\
\mathrm{T}_{c}\left({ }^{\circ} \mathrm{K}\right)\end{array}$} & \multicolumn{3}{|c|}{ Isp (sec) } & \multirow[b]{2}{*}{$\begin{array}{l}\text { Tankage } \\
\text { Fraction (\%) }\end{array}$} & \multirow[b]{2}{*}{$\begin{array}{l}\text { T/W } \\
\text { Ratio }\end{array}$} \\
\hline & $\begin{array}{r}5 \\
2900\end{array}$ & $\begin{array}{c}10 \\
2800\end{array}$ & $\begin{array}{c}30 \\
2600\end{array}$ & & \\
\hline $\begin{array}{r}\mathrm{O} / \mathrm{H} \mathrm{MR}=0.0 \\
1.0 \\
3.0 \\
5.0 \\
7.0\end{array}$ & $\begin{array}{l}941 \\
772 \\
647 \\
576 \\
514\end{array}$ & $\begin{array}{l}925 \\
762 \\
642 \\
573 \\
512\end{array}$ & $\begin{array}{l}891 \\
741 \\
631 \\
566 \\
508\end{array}$ & $\begin{array}{r}14.0 \\
7.4 \\
4.1 \\
3.0 \\
2.5\end{array}$ & $\begin{array}{r}3.0^{\circ} \\
4.8 \\
8.2 \\
11.0 \\
13.1\end{array}$ \\
\hline
\end{tabular}

- For $15 \mathrm{klbf}$ LANTR with chamber pressure $=2000$ psia and $\epsilon=500$ to 1

Fig. 3 Schematic/Characteristics of LOX-Augmented NTR 
Increasing the MR reduces the hydrogen mass and volume and decreases the $\mathrm{LH}_{2}$ tank size and mass. This feature provides important flexibility to vehicle designers allowing small LANTR-based transfer stages to be configured to accommodate "massand/or volume-constrained" launch vehicles. Compactness is especially important for LANTR deployment using the SSTO because of its small cargo bay dimensions.

Finally, once LUNOX becomes available in LLO to reoxidize the LANTR LTV, transition to a "reusable" mission architecture can occur, with formerly expendable vehicles delivering significant quantities of payload to LLO on each round trip cargo, as well as piloted mission. These capabilities are discussed in detail in the sections which follow.

\section{LUNAR MISSION / TRANSPORTATION SYSTEM GROUND RULES AND ASSUMPTIONS}

The ground rules and assumptions for the reference lunar mission examined in this study are summarized in Table 2. Provided are details on outbound and return payloads, parking orbits, mission velocity change $(\Delta V)$ requirements and duration, and SSTO characteristics. In addition to the primary $\Delta \mathrm{V}$ maneuvers indicated, midcourse correction maneuvers are also performed using a storable, bipropellant RCS system. Table 3 details assumptions for the LANTR LTV on primary and auxiliary propulsion, cryogenic tankage, thermal protection and boiloff rates, primary structure, and contingency factors used in this study.

An aluminum-lithium alloy "Weldalite" $\left(F_{\text {tu }}=111 \mathrm{ksi}, \rho=0.0976 \mathrm{lbm} / \mathrm{in}^{3}=2700 \mathrm{~kg} / \mathrm{m}^{3}\right)$ has been used for the cryogenic LOX and $\mathrm{LH}_{2}$ tanks and a graphite/epoxy composite IM7/977-2 ( $F_{\text {tu }}=91 \mathrm{ksi}$, $\rho=0.057 \mathrm{lbm} / \mathrm{in}^{3}=1577 \mathrm{~kg} / \mathrm{m}^{3}$ ) for non-pressurized primary structure in accordance with assumptions used for the SSTO-R reference configuration. Wall thicknesses for the $\mathrm{LH}_{2}$ tanks were calculated based on a 35 psi internal pressure and included hydrostatic loads using a " $4 \mathrm{~g}$ " load factor along with a safety factor of 1.5 . A $2.5 \%$ ullage was also assumed in this study. A 50 psi internal pressure was assumed for LOX tanks with wall thicknesses of $\sim 0.05$ inches.

A two inch helium-purged, multilayer insulation (MLI) system (at 50 layers per inch) is assumed for thermal protection of the LANTR's LOX

Table 2. Reference Lunar Mission Ground Rules and Assumptions

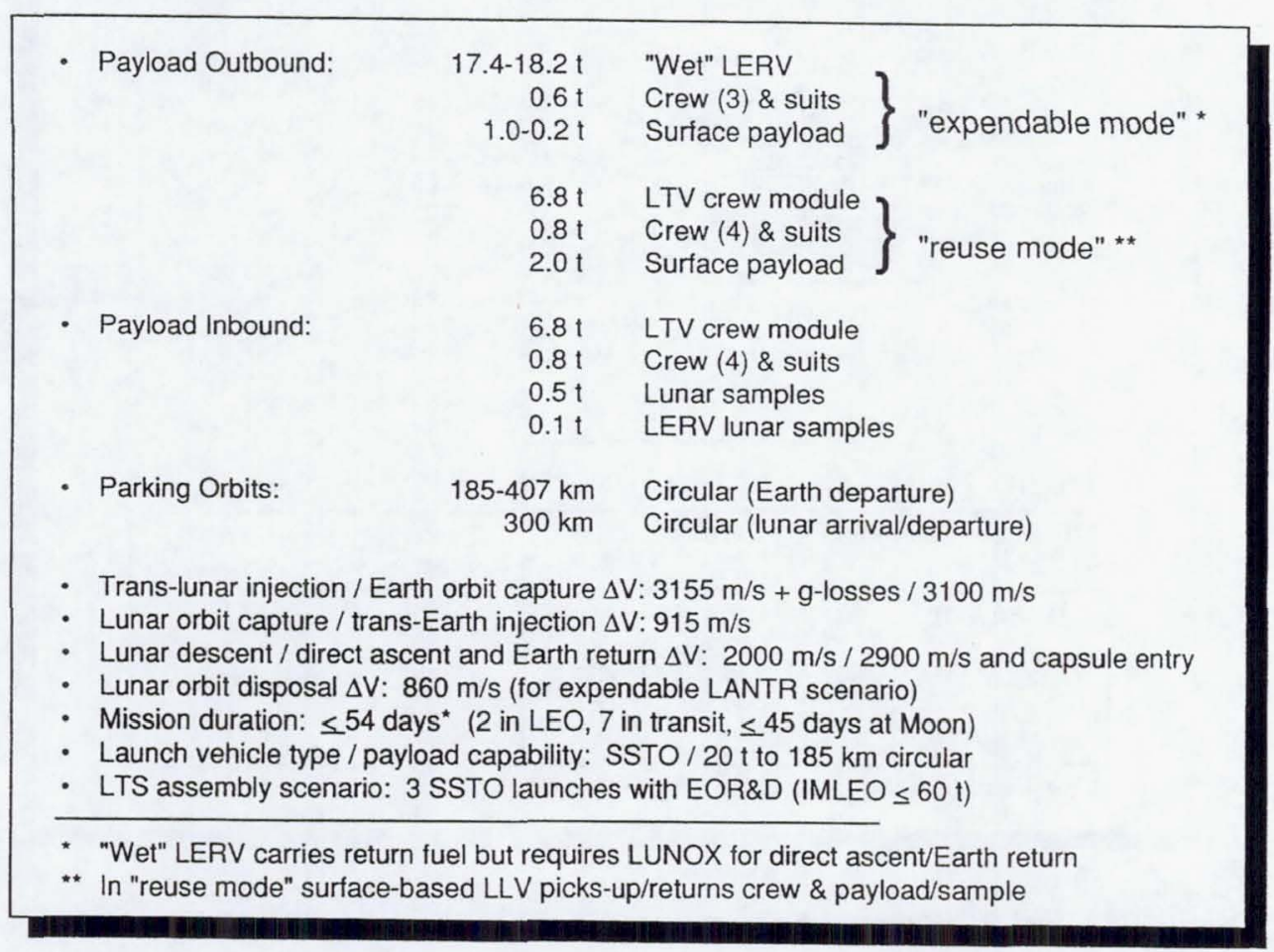


Table 3. LANTR Transportation System Assumptions

\begin{tabular}{|c|c|c|}
\hline - LANTR System: & $\begin{array}{l}\text { Propellants } \\
\text { Isp } \\
\text { External Shield Mass } \\
\text { Flight Reserve } \\
\text { Residuals } \\
\text { Cooldown (effective) }\end{array}$ & $\begin{array}{l}=\text { Cryogenic hydrogen and oxygen } \\
=940 \mathrm{~s}\left(@ \mathrm{O} / \mathrm{F} \mathrm{MR}=0.0 / \mathrm{LH}_{2} \text { only }\right) \\
=607 \mathrm{~s}(@ \mathrm{O} / \mathrm{F} \mathrm{MR}=4.0) \\
=545 \mathrm{~s}(@ \mathrm{O} / \mathrm{F} \mathrm{MR}=6.0) \\
=2.84 \mathrm{~kg} / \mathrm{MWt} \text { of reactor power } \\
=1 \% \text { of total tank capacity } \\
=1.5 \% \text { of total tank capacity } \\
=3 \% \text { of usable } \mathrm{LH}_{2} \text { propellant }\end{array}$ \\
\hline - RCS System: & $\begin{array}{l}\text { Propellant } \\
\text { Isp } \\
\text { Tankage }\end{array}$ & $\begin{array}{l}=\mathrm{N}_{2} \mathrm{O}_{4} / \mathrm{MMH} \\
=320 \mathrm{~S} \\
=5 \% \text { of total RCS propellants }\end{array}$ \\
\hline $\begin{array}{l}\text { Cryogenic } \\
\text { Tankage: }\end{array}$ & $\begin{array}{l}\text { Material } \\
\text { Diameter } \\
\text { Geometry } \\
\text { Insulation } \\
\text { LHz }_{2} \text { LOX Boiloff* }^{*}\end{array}$ & $\begin{array}{l}=\text { "Weldalite" Al/Li alloy } \\
=2.7 \mathrm{~m}(\mathrm{LOX}) / 4.6 \mathrm{~m}\left(\mathrm{LH}_{2}\right) \\
=\text { Cylindrical tank with } 2 / 2 \text { domes } \\
=2 \text { inches } \mathrm{MLI}+\text { micrometeoroid debris shield } \\
=1.31 / 2.44 \mathrm{~kg} / \mathrm{m}^{2} / \text { month (LEO @ 240 K) } \\
=0.56 / 0.90 \mathrm{~kg} / \mathrm{m}^{2} / \mathrm{month} \text { (in-space @ 172 K) } \\
\left.=1.91 / 3.68 \mathrm{~kg} / \mathrm{m}^{2} / \mathrm{month} \text { (LLO @ } 272 \mathrm{~K}\right)\end{array}$ \\
\hline - Primary Structure: & Material & $=$ Graphite/Epoxy Composite \\
\hline - Contingency: & \multicolumn{2}{|c|}{ Engine, shield , and stage dry mass $=15 \%$} \\
\hline
\end{tabular}

and $\mathrm{LH}_{2}$ cryogenic tanks. This insulation thickness exceeds the "ground hold" thermal protection requirements for "wet-launched" $\mathrm{LH}_{2}$ tanks which need a minimum of 1.5 inches of helium-purged insulation. 12 The installed density of the " 2 inch MLI system" is $\sim 2.62 \mathrm{~kg} / \mathrm{m}^{2}$, and the resulting $\mathrm{LH}_{2}$ boiloff rate in LEO is $\sim 1.31 \mathrm{~kg} / \mathrm{m}^{2} /$ month (based on an estimated heat flux of $\sim 0.22 \mathrm{~W} / \mathrm{m}^{2}$ at a LEO sink temperature of $\sim 240 \mathrm{~K}$ ). In lunar orbit, where the sink temperature and heat flux are estimated to be $\sim 272 \mathrm{~K}$ and $0.32 \mathrm{~W} / \mathrm{m}^{2}$, respectively, the $\mathrm{LH}_{2}$ boiloff rate increases by $\sim 46 \%$ to $1.91 \mathrm{~kg} / \mathrm{m}^{2} /$ month. The corresponding boiloff rates for LOX are also shown in Table 3. Finally, a $0.25 \mathrm{~mm}$ thick sheet of aluminum (corresponding to $\sim 0.682 \mathrm{~kg} / \mathrm{m}^{2}$ ) is included in the total tank weight estimates to account for micrometeoroid protection.

\section{LUNAR MISSION ARCHITECTURE DESCRIPTION}

The reference lunar scenario examined in this study assumes a split mission architecture involving both cargo and piloted missions operating initially in an "expendable mode." The piloted mission employs a "Iunar direct" flight profile and assumes the availability of LUNOX for lander refill and Earth return. 8,13 The mission flight profile is illustrated in Figure 4. Three SSTO flights, each with a payload capability of $\sim 20 \mathrm{t}$, are used to deliver the LTS elements consisting of the LANTR-powered LTV and its payload--the piloted lunar landing / Earth return vehicle (LERV) to LEO. Here the elements are assembled into an integrated spacecraft via a series of rendezvous and docking maneuvers (see Figures 4 and $5 b)$.

After 2 days in LEO for system checkout, a "single burn" trans-lunar injection (TLI) maneuver is performed which sends the coupled LTV/LERV on a trajectory to the Moon. Following a 3.5 day transit, the LANTR engine performs a second burn to achieve lunar orbit insertion (LOI). After a brief waiting period in LLO for proper landing site phasing, the LERV with its 3 person crew separates from the LANTR stage, deorbits and lands on the lunar surface. Shortly afterwards, the LANTR performs a short ( 0.6 minute) final burn to depart LLO and send the spent stage on a "long-term disposal" trajectory into heliocentric space.

The LERV consists of a "scaled-up" Apollo capsule mounted atop a combination service module/lander vehicle which uses either $L O X / \mathrm{LH}_{2}$ or LOX/liquid methane $\left(\mathrm{CH}_{4}\right)$ chemical engines. It lands on the lunar surface with its LOX tanks essentially "empty" but carries sufficient fuel $\left(\mathrm{LH}_{2}\right.$ or 


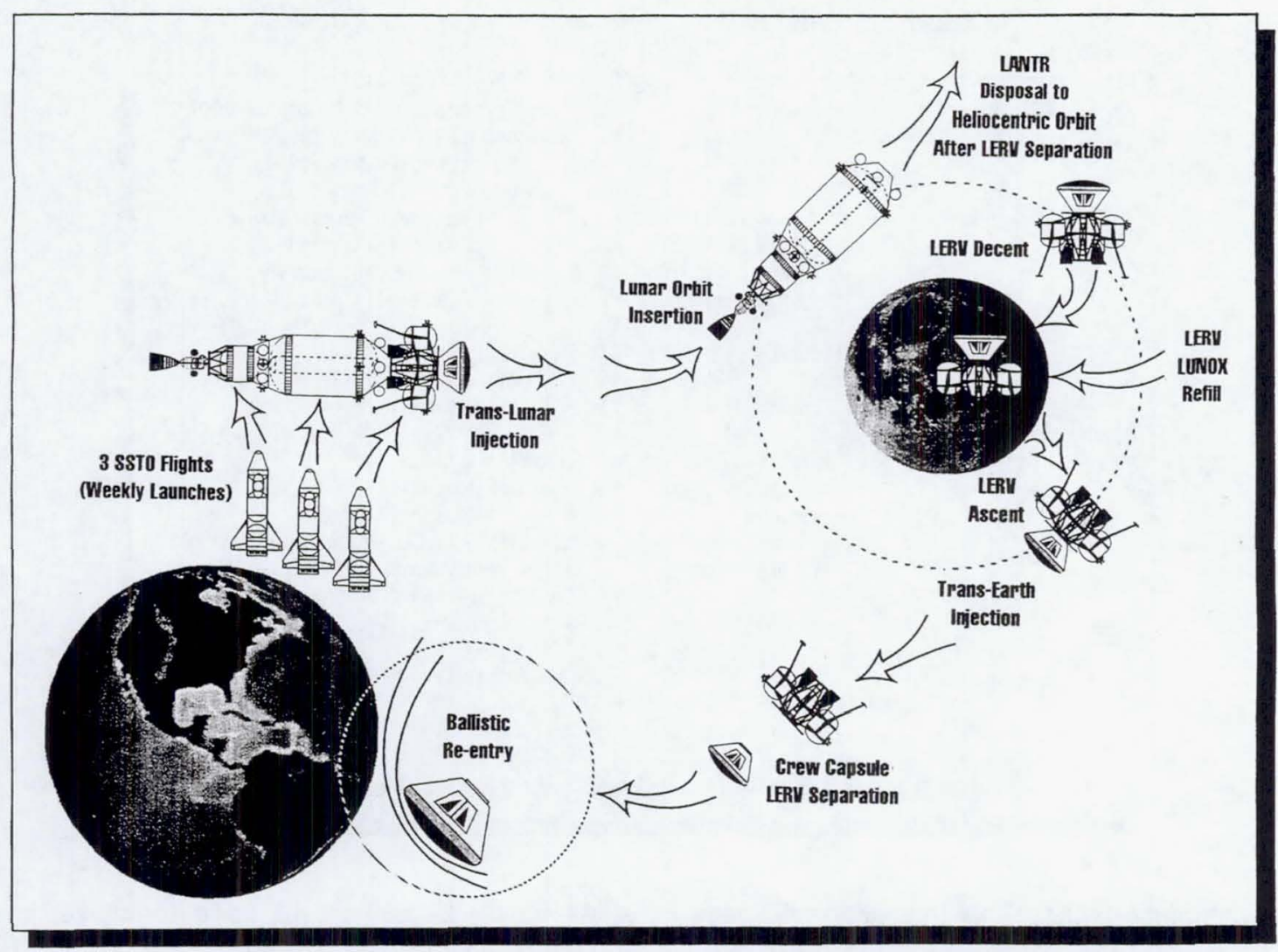

Fig. 4 Reference Piloted Mission Scenario Using SSTO, LANTR and LUNOX Technologies

$\mathrm{CH}_{4}$ ) for the return trip to Earth. Because of the limited life support capabilities of the LERV, the crew is sustained for extended periods by a surface habitation facility delivered on earlier cargo missions, as are the LUNOX production equipment and surface exploration equipment. 8 Near the end of the surface stay, the crew uses the surface tanker to transport and refill the LERV's LOX tank with $\sim 8 \mathrm{t}$ of LUNOX supplied by the production facility. Once reoxidized, the LERV, with crew and samples, ascends to a temporary lunar phasing orbit, then performs the trans-Earth injection (TEI) burn for the trip back. Near Earth, the lander stage is jettisoned and the crew module reenters ballistically.

\section{LTS VEHICLE DESCRIPTIONS / COMPARISONS}

The relative size and mass of various NTR/LANTR-powered LTV and chemical LERV combinations are shown in Figure 5. Table 4 summarizes LERV system assumptions and its mass breakdown both in low lunar orbit (IMLLO) and on the lunar surface (IMLS) prior to Earth return. The mass elements include the 3 crew, surface-landed payload (SP/L), the LERV's return crew capsule (LERC), and lunar landing stage, and returned lunar samples/payload (RP/L). The required amounts of LOX and fuel (either $\mathrm{LH}_{2}$ or $\mathrm{CH}_{4}$ ) for landing, as well as, quantities of LUNOX and fuel for ascent and Earth return are also shown.

To provide a point of comparison with the reference SSTO-launched and LANTR-powered vehicles, Figure $5 a$ shows a LOX/LH $H_{2}$ LERV and "all $\mathrm{LH}_{2}$ " NTR LTV configuration that uses the Space Shuttle orbiter and a Titan IV launch vehicle, respectively, for their delivery to LEO. The LERV's "wet" lander stage and crew capsule have a combined mass of $20 \mathrm{t}$ and are carried in the orbiter's payload bay "side-by-side." Once in orbit the capsule is installed atop the lander and the integrated LERV's systems are checked out.

Next, a 20 t "all $\mathrm{LH}_{2}$ " NTR-powered LTV is launched to LEO for Earth orbit rendezvous and docking (EOR\&D) with the LERV. A Titan IV booster, with an 86 foot $(\sim 26.2 \mathrm{~m})$ long payload fairing, is 


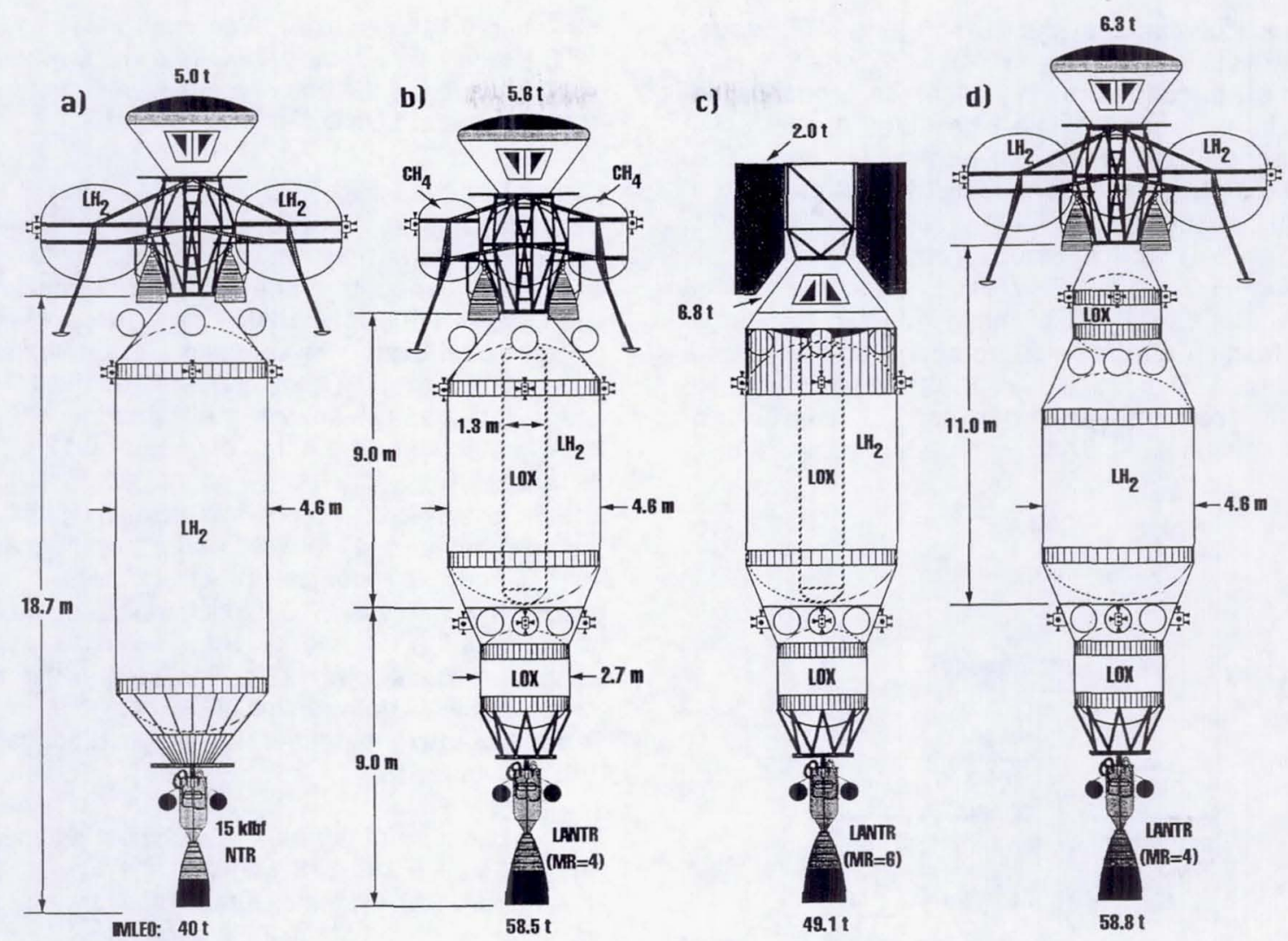

Fig. 5 Relative Size/Mass of NTR, LANTR and LERV Vehicles

Table 4. LERV System Assumptions and Characteristics

\begin{tabular}{|c|c|c|c|}
\hline - Propellant: & ${\mathrm{LOX} / \mathrm{LH}_{2}}_{2}$ & $\mathrm{LOX} / \mathrm{LH}_{2}$ & $\mathrm{LOX} / C H_{4}$ \\
\hline - MR / Isp: & $6.0 / 465 \mathrm{~s}$ & $6.0 / 465 s$ & $3.5 / 375 \mathrm{~s}$ \\
\hline - IMLLO / IMLS: & $16.0 / 16.8 \mathrm{t}$ & $19.0 \mathrm{t}$ & $18.5 \mathrm{t}$ \\
\hline - Crew (3) \& suits: & $0.6 \mathrm{t}$ & $0.6 \mathrm{t}$ & $0.60 \mathrm{t}$ \\
\hline$\cdot \mathrm{M}_{\mathrm{sPn}}$ & $0.4 \mathrm{t}$ & $1.04 t$ & $0.20 \mathrm{t}$ \\
\hline$\cdot M_{\text {LERC }}$ & $5.0 \mathrm{t}$ & $6.29 \mathrm{t}$ & $5.60 \mathrm{t}$ \\
\hline - $M_{\text {stape }}:$ & $\begin{array}{c}3.0 \mathrm{t} \\
\text { (15\% IMLEO) }\end{array}$ & $\begin{array}{c}2.85 \mathrm{t} \\
(15 \% \text { IMLS) }\end{array}$ & $\begin{array}{c}1.85 \mathrm{t} \\
(10 \% \text { IMLS) }\end{array}$ \\
\hline$\cdot M_{10 x}:$ & $5.0 \mathrm{t}$ & $5.93 \mathrm{t}$ & $6.82 \mathrm{t}$ \\
\hline $\begin{array}{l}-\mathrm{M}_{\text {tuo: }} \\
\text { - landing } \\
\text { - ascent / return }\end{array}$ & $\begin{array}{l}0.84 \mathrm{t} \\
1.16 \mathrm{t}\end{array}$ & $\begin{array}{l}0.99 \mathrm{t} \\
1.31 \mathrm{t}\end{array}$ & $\begin{array}{l}1.14 \mathrm{t} \\
2.30 \mathrm{t}\end{array}$ \\
\hline - $M_{\text {tunox: }}$ & $6.95 t$ & $7.85 \mathrm{t}$ & $8.05 \mathrm{t}$ \\
\hline$\cdot \mathrm{M}_{\mathrm{PPn}}$ & $0.10 \mathrm{t}$ & $0.10 \mathrm{t}$ & $0.10 \mathrm{t}$ \\
\hline
\end{tabular}


used to accommodate the $18.7 \mathrm{~m}$ long NTR stage. Total vehicle length after EOR\&D is 25 meters (see Figure 6 ). In contrast to the reference scenario, the NTR LTV performs a single 28 minute TLI burn only, leaving the LERV to accomplish the LOI burn. The added $\mathrm{LOX}_{\mathrm{L}} \mathrm{LH}_{2}$ propellant consumption results in a lower initial mass in low lunar orbit (IMLLO) of $\sim 16 t$ (see Table 4) and a reduced capability crew cab weighing $\sim 5.0 \mathrm{t}$. The LERV lander stage mass is set at $15 \%$ of the "wet" LERV mass in LEO. The same mass fraction and mission approach was proposed by General Dynamics ${ }^{14}$ in 1993 except that their scenario used a "Centaur-derived" TLI stage with a new, single $35 \mathrm{klbf} \mathrm{LOX} \mathrm{LH}_{2}$ chemical engine. It also

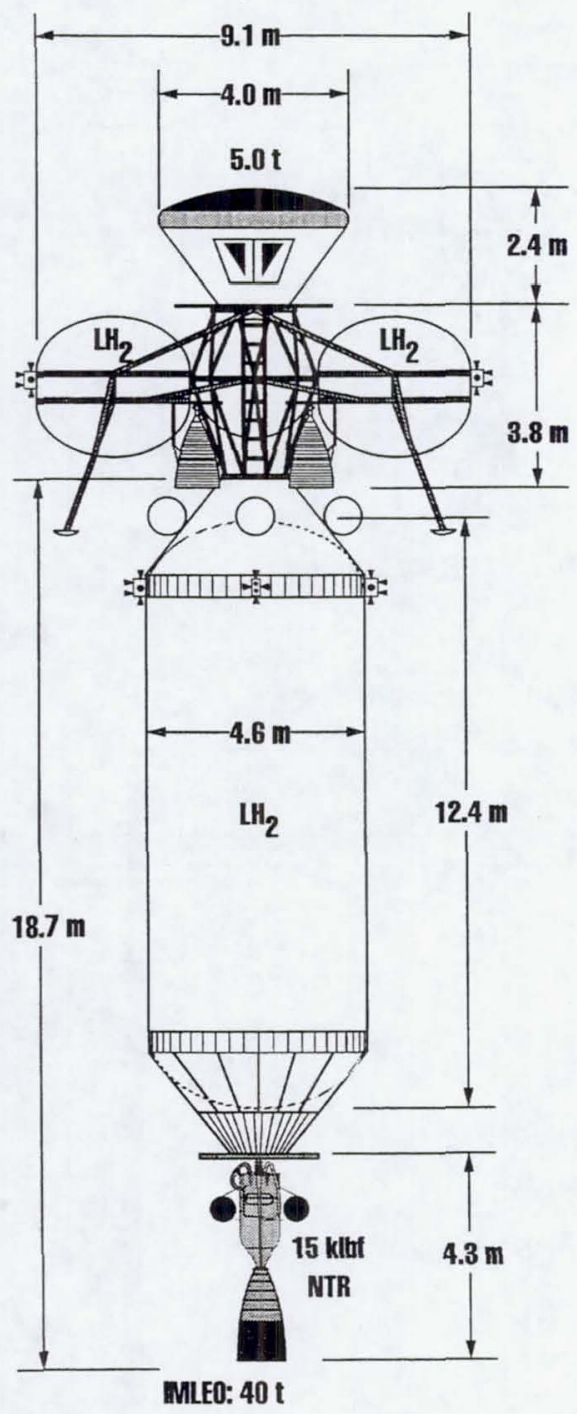

Fig. 6 NTR LTV and LERV Dimensions Using Shuttle and Titan IV Launch Vehicles assumed a lighter weight " 2 person" crew capsule (at $\sim 3.3 \mathrm{t}$ ) and had a total IMLEO in excess of the "40 t limit" because of the use of a chemical TLI stage and the absence of LUNOX utilization.

The "all $\mathrm{LH}_{2}$ " NTR TLI stage uses a single 15 klbf engine, dual turbopumps for improved reliability, and ternary carbide fuel elements. At the hydrogen exhaust temperature and nozzle inlet pressure of $2900 \mathrm{~K}$ and 2000 psia, respectively, the specific impulse is 940 s using a nozzle expansion ratio of 300 to 1 . Other elements of the NTR TLI stage include: (1) an external radiation shield for crew protection; (2) a $4.6 \mathrm{~m}$ diameter by $12.4 \mathrm{~m}$ long $\mathrm{LH}_{2}$ tank; (3) a forward cylindrical adaptor housing the RCS system, avionics and auxiliary power, and docking system; (4) forward and aft cylindrical band skirts; and (5) a conical thrust structure. The TLI stage "dry" mass is $~ 7.0 \mathrm{t}$ which includes $\sim 3.64 \mathrm{t}$ for the $15 \mathrm{klbf}$ NTR and shield. The RCS and $\mathrm{LH}_{2}$ propellant loads total $\sim 13 \mathrm{t}$. Included in this total is propellant to perform a small $(\sim 30 \mathrm{~m} / \mathrm{s})$ "trailing edge" lunar swingby maneuver for stage disposal after LERV separation.

Because of the high launch cost estimates for the Titan IV ( 190-375 M\$) and the Space Shuttle ( 450-550 M\$) systems, future lunar transportation costs could be substantially reduced if LTS elements can be efficiently packaged within the SSTO cargo bay. The most restrictive configuration is the $30 \mathrm{ft}$ cargo bay. Figure $5 b$ shows a " 3 element" vehicle configuration. The first SSTO flight delivers the "propulsion module" consisting of a small LANTR engine (producing $15 \mathrm{klbf}$ at MR $=0$ ) and a LOX tank which is $2.7 \mathrm{~m}$ in diameter and $3.0 \mathrm{~m}$ long and has a maximum capacity of $\sim 15 \mathrm{t}$. The propulsion module also contains: (1) a forward conical adaptor section (housing half of the total RCS propellant and hardware required for the lunar mission, modest avionics and auxiliary power, and docking system); (2) two cylindrical band skirts; and (3) aft thrust structure. The propulsion module "dry" mass is $\sim 5.0 \mathrm{t}$ and consists primarily of the LANTR engine at $\sim 2.7 t$ and its external radiation shield at $\sim 1.1 \mathrm{t}$. The propulsion module total mass and length are $\sim 20 \mathrm{t}$ and $9.0 \mathrm{~m}$, respectively. By contrast, a propulsion module with a $\mathrm{LH}_{2}$ tank the same size as the LOX tank would contain only $\sim 1 \mathrm{t}$ of $\mathrm{LH}_{2}$ and thus be far less mass-efficient than the present design.

The second SSTO launch one week later, delivers a $20 \mathrm{t}$ "propellant module" to LEO containing the $\mathrm{LH}_{2}$ tank, its forward and aft adaptors and docking systems, and the remainder of the RCS, avionics and auxiliary power. To stay within the " $9 \mathrm{~m}$ length limit " of the SSTO, the remaining oxygen 
required for the mission is contained within a "double-walled" and insulated internal LOX tank the same length as that of the $\mathrm{LH}_{2}$ tank at $\sim 8.0 \mathrm{~m}$. Its diameter is only $1.3 \mathrm{~m}$, however, compared to $4.6 \mathrm{~m}$ for that of the $\mathrm{LH}_{2}$ tank. The $\mathrm{LH}_{2}$ and internal LOX tanks contain $\sim 6.5 \mathrm{t}$ and $10.0 \mathrm{t}$ of fuel and oxidizer, respectively, but can accommodate up to $\sim 7.3 t$ of $\mathrm{LH}_{2}$ and $\sim 11.1 \mathrm{t}$ of $\mathrm{LOX}$ depending on mission requirements. The $9 \mathrm{~m}$ long "propellant module" has a dry mass of $\sim 3.3 \mathrm{t}$ and RCS, $\mathrm{LH}_{2}$ and $\mathrm{LOX}$ propellant loads of $0.3,6.5$, and $9.9 \mathrm{t}$, respectively.

After successful rendezvous and docking between the propulsion and propellant modules, the third and final SSTO launch delivers the LERV and its crew. Because of volume constraints, a $\mathrm{LOX} / \mathrm{CH}_{4}$ LERV is utilized and launched with the crew capsule positioned sideways next to the lander. Its maximum mass is limited to $\sim 18.5$ t to stay within the payload delivery capability of the LANTR-powered LTV and the total "mission-mass-limit" of $60 \mathrm{t}$. The LERV's $\mathrm{LOX} / \mathrm{CH}_{4}$ engines operate at a MR $=3.5$ and Isp = 375 s (see Table 4), and although their performance is less than the $\mathrm{LOX} / \mathrm{LH}_{2}$ system, methane is more easily stored on the Moon implying less boiloff and tank insulation mass. The LERV transports $\sim 2.3 t$ of "return methane" to the lunar surface and refills its LOX tank with just over $8 \mathrm{t}$ of LUNOX to return the LERV with its $5.6 \mathrm{t}$ crew capsule and $\sim 0.7 \mathrm{t}$ of crew and lunar samples back to Earth. The same LANTR LTV and LERV landing stage can deliver $~ 8.7 \mathrm{t}$ of lunar surface payload on "1-way" cargo missions.

When the crew capsule is mounted to the landing stage and the LERV mated to the LANTR LTV, the total spacecraft length and mass is $\sim 24.2 \mathrm{~m}$ and $58.5 \mathrm{t}$, respectively (see Figure 7 ). The LANTR engine operates at a MR $=4$ (Isp 607 s) which increases the thrust output by a factor of $\sim 3.2$--from $15 \mathrm{klbf}($ at $M R=0$ ) to $\sim 48.4 \mathrm{klbf}$. With this "enhanced" engine thrust-to-weight capability, g-losses drop to less than $50 \mathrm{~m} / \mathrm{s}$ and the TLI burn duration is $\sim 11.2$ minutes compared to 28 minutes for the "all $\mathrm{LH}_{2}$ " NTR system (Figure 5a). In fact, the total burn duration for the TLI, LOI and LLO disposal manuevers is just over 14 minutes --half that of the "all $\mathrm{LH}_{2}$ " NTR TLI stage.

Because the reactor fuel lifetime in the LANTR engine is $\sim 5$ hours at a hydrogen exhaust temperature of $2900 \mathrm{~K}$, the LANTR LTV is capable of performing many lunar missions in its lifetime, thereby reducing LTS recurring costs. Once LUNOX becomes available in LLO to "reoxidize" the expendable LANTR LTV (Figure $5 \mathrm{~b}$ ), the mission architecture can transition to a "reusable mode" with the same LANTR-powered LTV transporting a $6.8 \mathrm{t}$

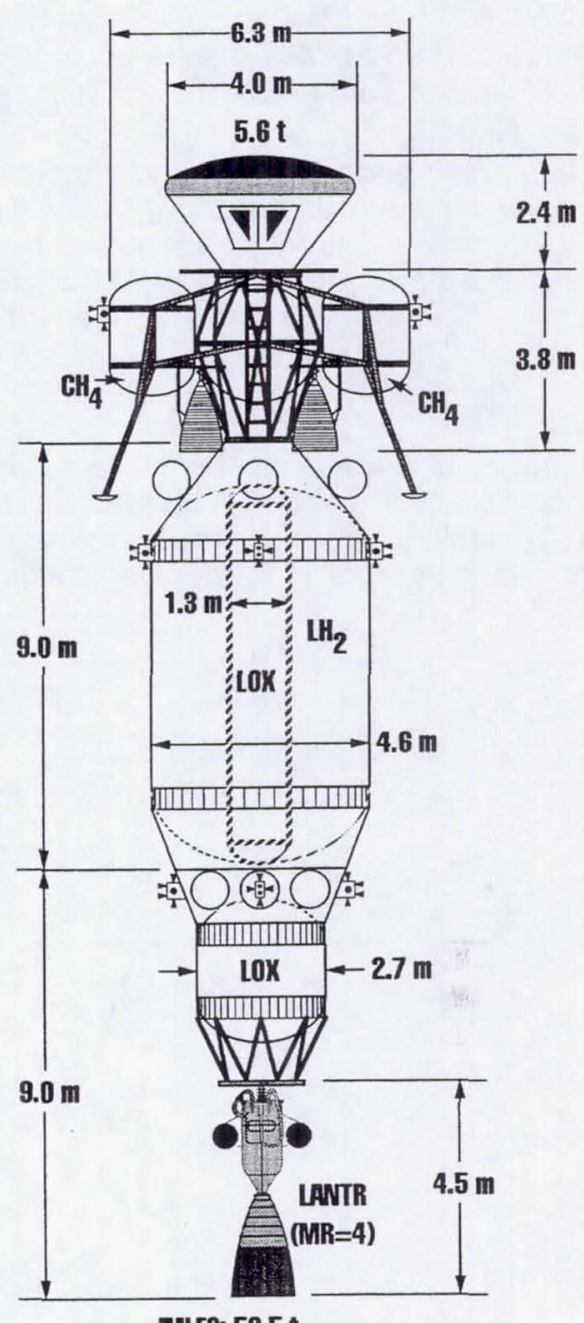

MLE0: $58.5 \mathrm{t}$

Fig. 7 LANTR LTV and LERV Dimensions Using "9 m Cargo Bay" SSTO

crew module plus $2 \mathrm{t}$ of surface payload to LLO (see Figure $5 \mathrm{c}$ ). Crew and cargo would then be ferried to the lunar surface by reusable LLVs that are now maintained and refueled at an established lunar outpost. In the "cargo-delivery mode," the crew capsule would be removed allowing the LANTR LTV to deliver $\sim 12$ t of cargo and "Earth-supplied $\mathrm{LH}_{2}$ " to LLO on each round trip mission. The required IMLEO for the reusable cargo mission is $\sim 52.4 \mathrm{t}$.

In the "reuse mode," the LANTR engine operates with a MR=6 (Isp 545 $s$ and thrust 61 klbf) both outbound and back to stay within the LOX and $\mathrm{LH}_{2}$ propellant limits of the LTV again demonstrating the versatility of the LANTR concept. The piloted and cargo vehicles would require refilling in LLO with 
$\sim 17.1$ and $9.7 \mathrm{t}$ of LUNOX, respectively, before returning to Earth. Also with total mission burn times for the piloted and cargo missions of $\sim 15.2$ and 12.9 minutes, respectively, the LANTR-powered LTV would be able to perform $\sim 20$ round trip piloted and or cargo missions over its reactor operational lifetime thereby improving lunar transportation costs. Refueling and reoxidizing of the LANTR LTV in LEO would be accomplished at a propellant depot resupplied by a "tanker version" of the SSTO.

Figure $5 d$ shows an alternative expendable piloted configuration possible using the " $45 \mathrm{ft}$ cargo bay" SSTO option. With $\sim 13.5 \mathrm{~m}$ of available length to work with instead of $9 \mathrm{~m}$, the supplemental LOX

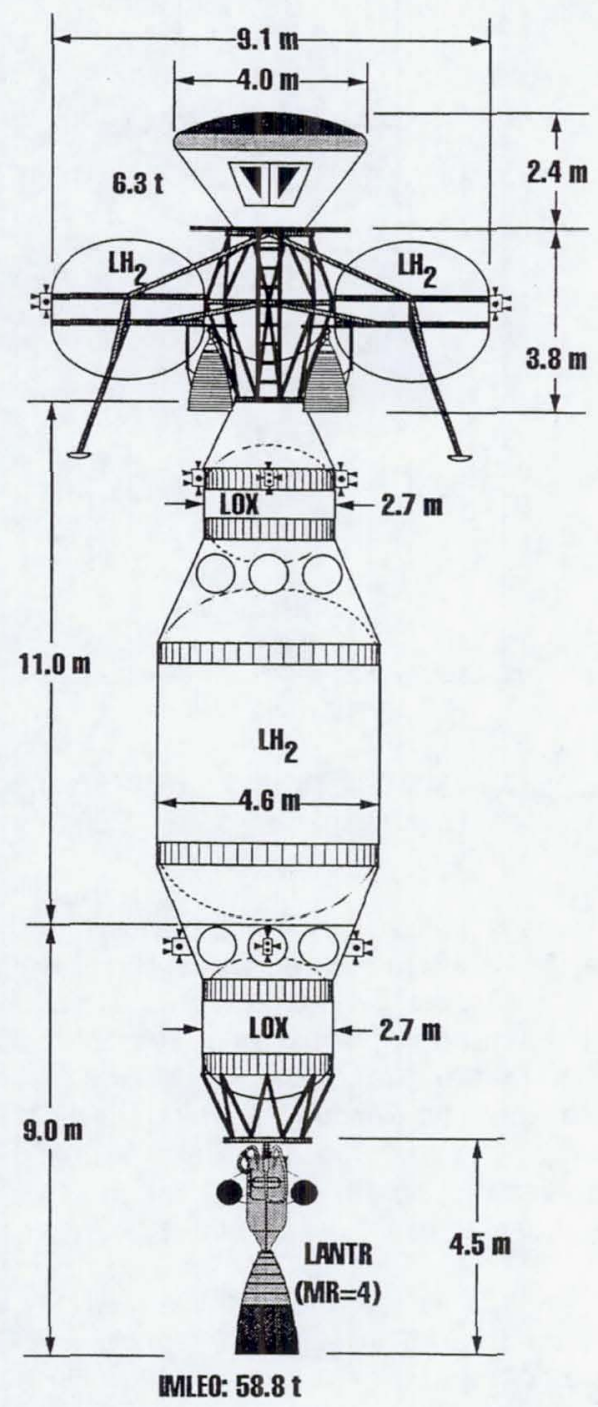

Fig. 8 LANTR LTV and LERV Dimensions Using "13.5 m Cargo Bay" SSTO tank in the propellant module can be removed from inside the $\mathrm{LH}_{2}$ tank improving safety and simplifying the design, construction and cost of the propellant module. The propellant module length is $\sim 11 \mathrm{~m}$ and includes a $7 \mathrm{~m}$ long $\mathrm{LH}_{2}$ tank and an $\sim 2.5 \mathrm{~m}$ long LOX tank at the same diameter as the propulsion module LOX tank. The LANTR LTV has an overall length $\sim 2 \mathrm{~m}$ longer than the configuration shown in Figure $5 b$ but it is slightly lighter since the "doublewalled" internal LOX tank is replaced by a singlewalled version. The larger payload bay also makes it possible to deploy a larger, more capable $\mathrm{LOX} / \mathrm{LH}_{2}$ LERV carrying a $6.3 \mathrm{t}$ crew capsule (see Figure 8) while staying within the $60 \mathrm{t}$ IMLEO limit. On "1-way" cargo missions, the $\mathrm{LOX} / \mathrm{LH}_{2}$ lander stage can deliver $\sim 9.2$ t of surface payload which is sufficient to accommodate all of the envisioned surface elements 8 needed to support the piloted mission.

\section{CONCLUDING REMARKS ON TRANSPORTATION SYSTEM COSTS}

While detailed LTS system (LANTR LTV and LERV) and operational costs are not yet available for determining the economics of the transportation system discussed here, some preliminary statements can be made on the basis of launch vehicle options and costs. Because LANTR engine use provides flexibility in packaging the LTV, it appears that viable human lunar missions are possible using SSTO and modest orbital assembly (Earth orbit rendezvous and docking of no more than three SSTO payloads). If SSTO launch costs of $\sim 40 \mathrm{M} \$$ can be truly realized, then 3 SSTO launches costing $120 \mathrm{M} \$$ could support higher performance lunar missions than the 2 launch scenario using the Space Shuttle and Titan IV vehicles costing $\sim 640 \mathrm{M} \$--a$ factor of 5 reduction in costs. With past studies 8 showing cost of payload to the lunar surface at $\sim 100 \mathrm{k} \$ / \mathrm{kg}$ ( $~ 8$ times higher than the cost to LEO), it can be inferred that delivery costs to the lunar surface of $\sim 20 \mathrm{k} \$ / \mathrm{kg}$ may be possible using SSTO, ISRU and LANTR technologies. It can also be easily argued that quoted SSTO costs are only estimates at this time while the the cost for Shuttle and Titan IV reflect actual operational costs. The technology challenges of the SSTO are substantial but so are the economic rewards. Without it, human lunar missons still appear possible using Shuttle,Titan IV, ISRU and NTR / LANTR technologies but at substantially higher costs.

\section{ACKNOWLEDGEMENTS}

The author wishes to express his thanks to management (Joe Nieberding and Don Palac) for their support during the course of this study and to John Mankins at NASA Headquarters' Advanced 
Concepts Office. His challenge to fit a LANTR-based system in the SSTO to support human lunar missions was the basis for this work. The author would also like to express his gratitude to Len Dudzinski (NASA Lewis) for converting the author's pencil drawings / layouts into the clear vehicle illustrations depicted in this paper and to Kent Joosten (NASA JSC) for use of the artwork depicted in Figure 2.

\section{REFERENCES}

1. R. E. Austin and S. A. Cook, "SSTO Rockets: Streamlining Access to Space," Aerospace America, Vol. 32, (November 1994), pp. 34-38.

2. America at the Threshold--America's Space Exploration Initiative, Report of the Synthesis Group, Available from the Superintendent of Documents, U. S. Government Printing Office, Washington, D. C. 20402 (June 1991).

3. NASA Strategic Plan, National Aeronautics and Space Administration, (May 1994).

4. Access to Space Study--Summary Report, Office of Space Systems Development, National Aeronautics and Space Administration, (January 1994).

5. T. S. Sullivan and D. S. McKay, Using Space Resources, NASA Johnson Space Center (1991).

6. L. A. Taylor and W. D. Carrier III, "The Feasibility of Processes for the Production of Oxygen on the Moon," in Engineering. Construction and Operations in Space III, New York, 1992, pp. 752-762.

7. C. C. Allen, R. V. Morris, and D. S. McKay, "Experimental Reduction of Lunar Mare Soil and Volcanic Glass," Journal of Geophysical Research, 99, 23, 173 (November 1994).

8. B. K. Joosten and L. A. Guerra, "Early Lunar Resource Utilization: A Key to Human Exploration," AlAA-93-4784, American Institute of Aeronautics and Astronautics (September 1993).

9. E. L. Christiansen, et al., "Conceptual Design of a Lunar Oxygen Pilot Plant," Eagle Engineering Report No. 88-182, Eagle Engineering, Inc., Houston, Texas (July 1, 1988).

10. S. K. Borowski et al., "A Revolutionary Lunar Space Transportation System Architecture Using Extraterrestrial LOX-Augmented NTR Propulsion," AIAA-94-3343, American Institute of Aeronautics and Astronautics (June 1994).
11. S. K. Borowski, D. W. Culver, and M. J. Bulman, "Human Exploration and Settlement of the Moon Using LUNOX-Augmented NTR Propulsion," in Proc. 12th Symposium on Space Nuclear Power and Propulsion, AIP Conf. Proc. No. 324, January 1995, Vol. 1, pp. 409-420.

12. R. H. Knoll, R. J. Stochl, and R. Sanabria, "A Review of Candidate Multilayer Insulation Systems for Potential Use of Wet-Launched $\mathrm{LH}_{2}$ Tankage for the Space Exploration Initiative Lunar Mission," AlAA-91-2176, American Institute of Aeronautics and Astronautics (June 1991).

13. R. M. Zubrin, "The Design of Lunar and Mars Transportation Systems Utilizing Extraterrestrial Resources," IAA-92-0161, 43rd Congress of the International Astronautical Federation, Washington, DC, (August 28-September 5, 1992).

14. J. M. Lenorovitz, "GD Goal: Lower Cost Manned Lunar Missions," Aviation Week and Space Technology, (January 18, 1993), pp. 42-45. 
Public reporting burden for this collection of information is estimated to average 1 hour per response, including the time for reviewing instructions, searching existing data sources, gathering and maintaining the data needed, and completing and reviewing the collection of information. Send comments regarding this burden estimate or any other aspect of this collection of information, including suggestions for reducing this burden, to Washington Headquarters Services. Directorate for Information Operations and Reports, 1215 Jefferson Davis Highway, Suite 1204, Arlington, VA 22202-4302, and to the Office of Management and Budget, Paperwork Reduction Project (0704-0188), Washington, DC 20503.

\begin{tabular}{|l|l|l|}
\hline 1. AGENCY USE ONLY (Leave blank) & $\begin{array}{c}\text { 2. REPORT DATE } \\
\text { October } 1995\end{array}$ & $\begin{array}{r}\text { 3. REPORT TYPE AND DATES COVERED } \\
\text { Technical Memorandum }\end{array}$
\end{tabular}

4. TITLE AND SUBTITLE

Human Lunar Mission Capabilities Using SSTO, ISRU and LOX-Augmented NTR Technologies-A Preliminary Assessment

6. $A U T H O R(S)$

Stanley K. Borowski

7. PERFORMING ORGANIZATION NAME(S) AND ADDRESS(ES)

National Aeronautics and Space Administration

Lewis Research Center

Cleveland, Ohio 44135-3191

9. SPONSORING/MONITORING AGENCY NAME(S) AND ADDRESS(ES)

National Aeronautics and Space Administration

Washington, D.C. 20546-0001
5. FUNDING NUMBERS

WU-242-10-01

8. PERFORMING ORGANIZATION

REPORT NUMBER

E-9973

10. SPONSORING/MONITORING AGENCY REPORT NUMBER

NASA TM-107095

AIAA-95-2631

11. SUPPLEMENTARY NOTES

Prepared for the 31st Joint Propulsion Conference and Exhibit cosponsored by AIAA, ASME, SAE, and ASEE, San

Diego, California, July 10-12, 1995. Responsible person, Stanley K. Borowski, organization code 6850, (216) 977-7091.

12a. DISTRIBUTIONAVAILABILTYY STATEMENT

12b. DISTRIBUTION CODE

Unclassified - Unlimited

Subject Categories 16 and 20

This publication is available from the NASA Center for Aerospace Information, (301) 621-0390.

13. ABSTRACT (Maximum 200 words)

The feasibility of conducting human missions to the Moon is examined assuming the use of three "high leverage" technologies: (1) a single-stage-to-orbit (SSTO) launch vehicle, (2) "in-situ" resource utilization (ISRU)--specifically "lunarderived" liquid oxygen (LUNOX), and (3) LOX-augmented nuclear thermal rocket (LANTR) propulsion. Lunar transportation system elements consisting of a LANTR-powered lunar transfer vehicle (LTV) and a chemical propulsion lunar landing/Earth return vehicle (LERV) are configured to fit within the "compact" dimensions of the SSTO cargo bay (diameter: $4.6 \mathrm{~m} / \mathrm{length}: 9.0 \mathrm{~m}$ ) while satisfying an initial mass in low Earth orbit (IMLEO) limit of $\sim 60 \mathrm{t}$ (3 SSTO launches). Using $~ 8 \mathrm{t}$ of LUNOX to "reoxidize" the LERV for a "direct return" flight to Earth reduces its size and mass allowing delivery to LEO on a single $20 \mathrm{t}$ SSTO launch. Similarly, the LANTR engine's ability to operate at any oxygen/ hydrogen mixture ratio from 0 to 7 with high specific impulse ( $\sim 940$ to $515 \mathrm{~s})$ is exploited to reduce hydrogen tank volume, thereby improving packaging of the LANTR LTV's "propulsion" and "propellant modules". Expendable and reusable, piloted and cargo missions and vehicle designs are presented along with estimates of LUNOX production required to support the different mission modes. Concluding remarks address the issue of lunar transportation system costs from the launch vehicle perspective.

14. SUBJECT TERMS

LOX-augmented NTR; LANTR; LUNOX; Single-stage-to-orbit; SSTO; ISRU; Lunar transportation system; Lunar landing/Earth return vehicle; LERV; LTV

17. SECURTYY CLASSIFICATION OF REPORT

Unclassified
18. SECURTYY CLASSIFICATION OF THIS PAGE

Unclassified
19. SECURITY CLASSIFICATION OF ABSTRACT Unclassified 